\title{
Cross Flow Analysis over the Jet Pumps of a BWR-5 Reactor
}

\author{
G. Soto-Mendoza $\left(\mathbb{D},{ }^{1}\right.$ A. Armenta-Molina ${ }^{D},{ }^{1}$ S. Pérez-Montejo, ${ }^{1}$ \\ L.H. Hernández-Gómez $\mathbb{D}^{1}{ }^{1}$ P. Ruiz-López, ${ }^{2}$ G.M. Urriolagoitia-Calderón, ${ }^{1}$ \\ and J.A. Beltrán-Fernández ${ }^{1}$ \\ ${ }^{1}$ Instituto Politécnico Nacional, ESIME Unidad Zacatenco, Sección de Estudios de Posgrado e Investigación, Edificio 5, 3er. Piso, \\ Unidad Profesional Adolfo López Mateos, Col. Lindavista, Alc. Gustavo A. Madero, 07738 Ciudad de México, Mexico \\ ${ }^{2}$ Comisión Nacional de Seguridad Nuclear y Salvaguardias, Dr. José Ma. Barragán, No. 779, Colonia Narvarte, \\ Alc. Benito Juárez, C.P. 03020, Ciudad de México, Mexico
}

Correspondence should be addressed to L.H. Hernández-Gómez; luishector56@hotmail.com

Received 17 August 2020; Revised 27 February 2021; Accepted 13 March 2021; Published 27 March 2021

Academic Editor: Han Zhang

Copyright (c) 2021 G. Soto-Mendoza et al. This is an open access article distributed under the Creative Commons Attribution License, which permits unrestricted use, distribution, and reproduction in any medium, provided the original work is properly cited.

\begin{abstract}
The recirculation system of a BWR-5 has 20 jet pumps. They are submerged in water in the cylindrical annular zone of the reactor. Their main function is the development of a forcing flow through the nuclear core. It increases the power of the reactor compared with the one obtained by natural circulation. These components have an important safety function in the operation of the reactor. In accordance with document BWRVIP-41 R4, it was concluded that the vibration induced by cross flow over the jet pump assemblies is one of the degradation mechanisms of such pumps. In this paper, the vibration induced by the cross flow at a jet pump assembly BWR-5 was analyzed. A numerical approach was developed. The natural frequencies were obtained, considering the Fluid-Structure Interaction (FSI). The first natural frequency was $25.7 \mathrm{~Hz}$. A Computational Fluid Dynamics (CFD) analysis was carried, in conjunction with the Power Spectral Density (PSD). A frequency of vortex generation of $0.48 \mathrm{~Hz}$ was obtained. A vortex generation analysis was carried out with the Q-criteria. The results showed that resonance conditions are unlikely. Therefore, the structural integrity of the jet pump assemblies is maintained.
\end{abstract}

\section{Introduction}

The jet pumps have an important safety function in the operation of a Boiling Water Reactor of the fifth generation (BWR-5). They are components of the recirculation system, which keeps the core reactor cool. For this reason, it is important to maintain its structural integrity and the required safety margins in all conditions of operation. However, there are some Nuclear Power Plants (NPPs) that have reported some failures in these components. As a result, some shutdowns have taken place until the repairs have been adequately accomplished. Besides, the unscheduled and long shutdowns generate economic losses.

One of the high-priority projects, which is managed by the US Nuclear Regulatory Commission and EPRI, is related to the degradation of the jet pumps [1]. Based on the BWRVIP-41-R4, it is concluded that the mechanisms of degradation due to flow-induced vibration are [2] (1) recirculation pump vane passing frequency, (2) turbulent fluid flow within the jet pump, (3) leakage flow at the slip joint between the mixer and the diffuser of the jet pump, and (4) cross flow over the jet pumps in the cylindrical annular zone of the reactor. The main interest of this paper is focused on the last case.

The jet pumps operate submerged in water inside the primary circuit. Under these conditions, the natural frequencies of such pumps are lower with respect to the ones in the air. So, this condition must be considered to avoid a wrong estimation of the dynamic response. The added mass method is used for this purpose. However, the evaluation of the natural frequencies of a structure submerged in a fluid is not straightforward. The governing equations of the fluid flow have to be solved. They cannot be obtained easily when the geometry of the structure is complex. Besides, the 
structural motions, stresses, and pressure must be considered. Solutions can be obtained with CFD (Computational Fluid Dynamics) techniques or by experimental measurements. In a numerical analysis, this problem may be solved by means of the Fluid-Structure Interaction (FSI). The displacement of the structure is considered as a boundary condition in the equations of the fluid. The equations of the movement of the structure include the fluid forces [3].

Regarding the cross flow, it has been widely studied for regular geometries such as cylinders or rectangular bars. However, the geometry of the jet pumps is more complex, because they are confined in a cylindrical annular region and the flow of water around these pumps is almost parallel to the axial axis at the top. Conversely, it is perpendicular to such axis at the bottom. A combination of the two flows is below the middle zone.

The jet pumps are important internal components of a BWR reactor. They keep the core reactor flooded. For this reason, it must be ensured that the cross flow degradation mechanism does not affect their performance. Cross flow generates vortices at the external surface of the jet pump. As a result, there is a pressure change that generates instability and may induce undesired resonance. For this reason, it is important to calculate the frequency of these vortices to ensure that the component operates with structural integrity.

The purpose of this paper is to present the methodology for the analysis of the vibration induced by the cross flow over the jet pumps of a BWR-5. Due to the complexity of the problem, a numerical approach has been followed.

\section{Statement of the Problem}

Jet pumps are part of the Reactor Recirculation System and provide forced circulation of water through the core. Higher levels of power are allowed than those obtained through natural circulation. Besides, the external flow is reduced. Such system has two external headers or loops. Each one has a suction valve, a recirculation pump, a control flow valve, a discharge valve, instrumentation, a connection pipe with the reactor vessel, and five jet pump assemblies $[4,5]$.

Jet pump assemblies are located at the cylindrical annular region of the reactor. A schematic typical configuration is shown in Figure 1. Each assembly has a riser and two jet pumps. Every jet pump has a mixer and a diffuser, and they are interconnected by a slip joint (see Figure 1). Its purpose is to reduce the vertical differential thermal stresses produced by the expansion of the carbon steel (pressure vessel) and the stainless steel (vessel internals). Therefore, the jet pump assemblies are flexible components $[2,4,5]$.

The convergent nozzle of the pump increases the flow and, simultaneously, there is a pressure drop. Under these conditions, a suction flow is developed from the annular zone of the vessel. The driven and the suction flows are combined at the mixer section and then pass through the diffuser. In this component, the pressure increases, and the flow velocity diminishes. Under normal conditions of operation, one-third of the total flow at the core is taken from the discharge of the recirculation pumps. The other twothirds are taken from the jet pumps $[4,5]$.

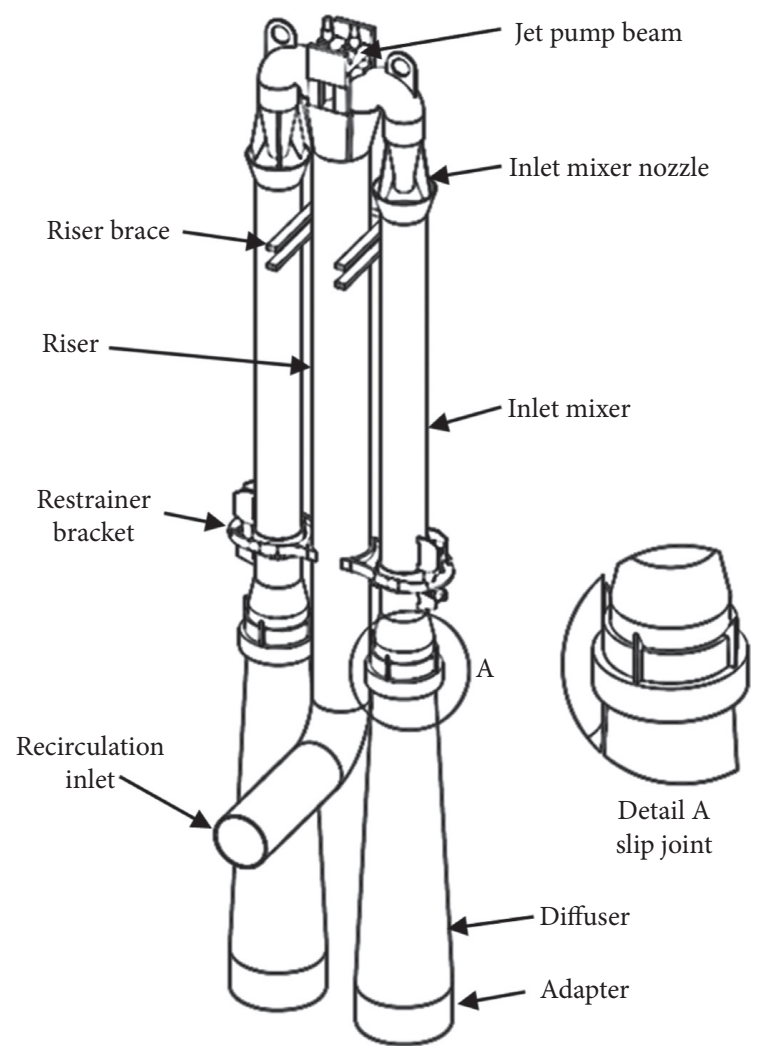

FIGURE 1: Jet pump assembly.

In a BWR-5, the flow is not totally perpendicular over the jet pumps. Most of the cross flow studies consider simple geometries and regular arrangements. Appendix N, Part $\mathrm{N}-1300$ of Section III of the ASME code, which is a nonmandatory appendix, addresses the flow-induced vibration of tubes and bundles of tubes due to cross flow.

The analysis of the fluid flow over jet pumps involves the solution of the Navier-Stokes equations. However, this simplified approach is not advisable to be used because the effects of viscosity must be considered. The solution can be obtained by an iterative approach. A numerical analysis can be carried out. Besides, the evaluation of vortices involves a transitory fluid analysis.

\section{Methodology}

The following steps were followed in the evaluation of the cross flow at the jet pumps in a BWR-5:

(1) The natural frequencies of the jet pump assembly submerged in water, by means of an analysis of the Structure Fluid Interaction (FSI), were calculated

(2) A transient analysis of the fluid in the cylindrical annular zone of the reactor, by means of Computational Fluid Dynamics (CFD), was carried on. The trajectory of the fluid flow was identified. In this way, the critical zones, which are affected by the cross flow, were identified. The variation of the velocity was calculated

(3) The frequency of vortices by means of the Power Spectral Density (PSD) was estimated. This is a 
procedure, which has been used to transform a signal from the time domain to the frequency domain. Accordingly, the frequency of the vortices can be obtained

(4) Evaluation of the results: the natural frequencies of the jet pump assembly were compared with the frequencies of vortex generation. The vortices were visualized with the $Q$ criterion. It was verified that resonance conditions cannot be developed. Besides, the ASME code was taken as a reference to verify that the code criteria were also met. In this way, the structural integrity of the jet pumps assembly is ensured

\section{Theoretical Basis}

4.1. Structural Dynamic Analysis. The governing nonlinear equation for a Dynamic Structural Analysis is the following [6]:

$$
[M]\{\ddot{u}\}+[C]\{\dot{u}\}+[K]\{u\}=\{F(t)\} .
$$

In this case, $[M]$ is the mass matrix, $[C]$ is the damping matrix, $[K]$ is the stiffness matrix, and $\{F\}$ is the force vector. The acceleration, velocity, and displacement vectors are $\{\ddot{u}\}$, $\{\dot{u}\}$, and, $\{u\}$, respectively. $(t)$ is time.

The natural frequencies and the mode of vibrations are obtained with a modal analysis. Free vibration is assumed, and the mass and stiffness matrices are constant. In this case, the following equation is obtained:

$$
\left(-\omega_{n}^{2}[M]+[K]\right)\{\varnothing\}_{n}=\{0\}
$$

where $\{\varnothing\}_{n}$ is an eigenvector. It represents the vibration modes and $\omega_{n}$ is the natural circular frequency. The natural frequencies $f_{n}$ are

$$
f_{n}=\frac{\omega_{n}}{2 \pi}
$$

4.2. Evaluation of the Natural Frequencies of a Body Submerged in a Fluid. The added mass method is used to obtain the natural frequencies of a body submerged in a fluid. However, a closed-form expression for the fluid forces is unlikely when the geometry of the structure is complex. This is the case of the jet pump assembly. The structural motion, as a boundary condition, was considered. Besides, stresses and pressure were integrated into the solution. In the case of this paper, CFD (computational fluid dynamics) was used. A Fluid-Structure Interaction (FSI) analysis has to be carried on. The following equation has to be solved in a harmonic oscillatory motion $[6,7]$ :

$$
\left[\begin{array}{cc}
-\omega^{2} M_{s}+j \omega C_{s}+K_{s} & -R \\
-\omega^{2} \rho_{0} R^{T} & -\omega^{2} M_{f}+j \omega C_{f}+K_{f}
\end{array}\right]\left\{\begin{array}{l}
U \\
p
\end{array}\right\}=\left\{\begin{array}{c}
F_{s} \\
F_{f}
\end{array}\right\} .
$$

In this case, $\left[M_{s}\right]$ is the mass matrix of the structure, $\left[M_{f}\right]$ is the mass matrix of the fluid, $\left[C_{s}\right]$ is the damping matrix of the structure, $\left[C_{f}\right]$ is the damping matrix of the fluid, $\left[K_{s}\right]$ is the stiffness matrix of the structure, $\left[K_{f}\right]$ is the stiffness matrix of the fluid, $[R]$ is the coupling matrix and takes into account the area associated with each node on the fluid-structure interface, $\{U\}$ is the displacement vector, $\{p\}$ is the pressure vector, $\left\{F_{s}\right\}$ is the vector of structural loads, $\left\{F_{f}\right\}$ is the vector of the fluid loads, and $\omega$ is the natural circular frequency. The natural frequency is obtained by equation (3).

4.3. Computational Fluid Dynamics Analysis. The numerical method, which was used for this analysis, is the Reynoldsaveraged Navier-Stokes (RANS) (equations (5) and (6)) and the turbulence model is $k-\varepsilon$. The transport equations for the realizable $k-\varepsilon$ model are equations $(7)$ and $(8)[8,9]$.

$$
\begin{aligned}
\frac{\partial \rho}{\partial t}+\frac{\partial}{\partial x_{i}}\left(\rho u_{i}\right) & =0 \\
\frac{\partial}{\partial t}\left(\rho u_{i}\right)+\frac{\partial}{\partial x_{j}}\left(\rho u_{i} u_{j}\right) & =-\frac{\partial p}{\partial x_{i}}+\frac{\partial}{\partial x_{j}}\left[\mu\left(\frac{\partial u_{i}}{\partial x_{j}}+\frac{\partial u_{j}}{\partial x_{i}}-\frac{2}{3} \delta_{i j} \frac{\partial u_{l}}{\partial x_{l}}\right)\right]+\frac{\partial}{\partial x_{j}}\left(-\rho \overline{u_{i}^{\prime} u_{j}^{\prime}}\right), \\
\frac{\partial}{\partial t}(\rho k)+\frac{\partial}{\partial x_{j}}\left(\rho k u_{j}\right) & =\frac{\partial}{\partial x_{j}}\left[\left(\mu+\frac{\mu_{t}}{\sigma_{k}}\right) \frac{\partial k}{\partial x_{j}}\right]+G_{k}+G_{b}-\rho \varepsilon-Y_{M}+S_{k} \\
\frac{\partial}{\partial t}(\rho \varepsilon)+\frac{\partial}{\partial x_{j}}\left(\rho \varepsilon u_{j}\right) & =\frac{\partial}{\partial x_{j}}\left[\left(\mu+\frac{\mu_{t}}{\sigma_{\varepsilon}}\right) \frac{\partial \varepsilon}{\partial x_{j}}\right]+\rho C_{1} S \varepsilon-\rho C_{2} \frac{\varepsilon^{2}}{k+\sqrt{v \varepsilon}}+C_{1 \varepsilon} \frac{\varepsilon}{k} C_{3 \varepsilon} G_{b}+S_{\varepsilon} \\
C_{1} & =\max \left[0.43, \frac{\eta}{\eta+5}\right] ; \\
\eta & =S \frac{k}{\varepsilon} ; \\
S & =\sqrt{2 S_{i j} S_{i j}},
\end{aligned}
$$


where $\rho$ is the density, $t$ is the time, $x_{i}$ are the coordinates along the $x_{i}$ axis $(i=1,2,3), u_{i}$ is the instantaneous velocity vector, $u_{j}$ is the velocity fluctuation vector, $p$ is the pressure, $\mu$ is the viscosity, $\mu_{t}$ is the eddy viscosity, $\delta_{i j}$ Krönecker's delta, $l$ is the macroscopic length scale, $k$ is the turbulence kinetic energy, and $e$ is the turbulence dissipation rate. $G_{k}$ is the generation of turbulence kinetic energy due to the mean velocity gradients. $G_{b}$ is the generation of turbulence kinetic energy due to buoyancy. $Y_{M}$ is the contribution of the fluctuating dilatation in compressible turbulence to the overall dissipation rate. $C_{1 \varepsilon}$ and $C_{2}$ are constants. $\sigma_{k}$ and $\sigma_{\varepsilon}$ are the turbulent Prandtl numbers for $k$ and $e . S_{k}$ and $S_{\varepsilon}$ are user-defined source terms. $S_{i j}$ is the rate of the strain tensor.

4.4. Power Spectral Density (PSD). The movement of the fluid is chaotic in a turbulent flow; that is, variables such as speed and pressure will have a random value within a certain range. The response of a turbulent excitation is usually estimated empirically. The evaluation can be done with the PSD. The analyzed parameter, as a function of time, is filtered with this procedure and can be related to the frequency of the vortices.

This can be done from the time domain to the frequency domain. It is defined as $[3,10]$

$$
\text { Power Spectral Density }=\frac{\left(a_{k}^{2}+b_{k}^{2}\right)}{2\left(f_{k}-f_{k-1}\right)},
$$

where $a_{k}$ and $b_{k}$ are the coefficients of the Fourier series.

$$
\begin{gathered}
a_{k}=\frac{2}{T} \int_{0}^{T} P(t) \cos \frac{2 \pi k}{T} t \mathrm{~d} t, \\
b_{k}=\frac{2}{T} \int_{0}^{T} P(t) \sin \frac{2 \pi k}{T} t \mathrm{~d} t .
\end{gathered}
$$

\section{Numerical Analysis}

A workstation with two $3.2 \mathrm{GHz}$ processors, $64 \mathrm{~GB}$ RAM, and 32 cores was used to perform the numerical simulation. A model of a jet pump assembly (see Figure 2) was developed with this infrastructure. For this purpose, it was assumed that the jet pumps were made with AISI 304L, low carbon stainless steel. The operation conditions are summarized in Table 1, and Figure 3 illustrates the zone, in which they take place.

The density and viscosity of the water are dependent on the temperature. They were obtained from the open literature [12]. The density of the water at $278{ }^{\circ} \mathrm{C}$ is $754 \mathrm{~kg} / \mathrm{m}^{3}$ and the dynamic viscosity is $9.48 \times 10-5 \mathrm{~kg} / \mathrm{m}$-s. The driven mass flow is one-third of the total flow of water through the core reactor.

5.1. Natural Frequencies of the Jet Pump Assembly Submerged in Water. The evaluation of the natural frequencies of a jet pump assembly submerged in water was done with a modal analysis. For this purpose, the ACT acoustic module of ANSYS was used.

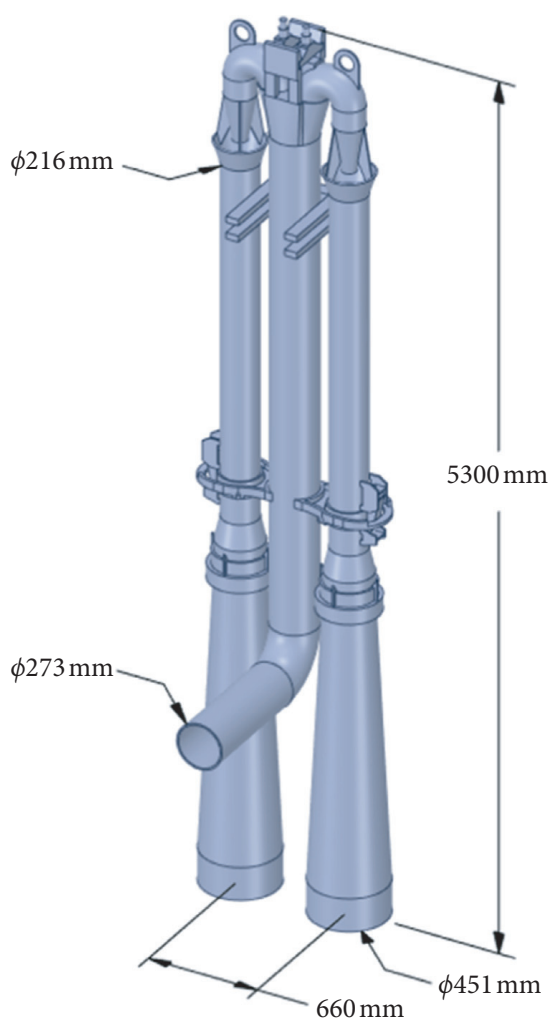

Figure 2: Model of the jet pump assembly.

TABle 1: Parameters of operation $[2,11,13]$.

\begin{tabular}{lc}
\hline Parameter & Value \\
\hline $\begin{array}{l}\text { Inlet pressure at the core of the } \\
\text { reactor (1) }\end{array}$ & $1060 \mathrm{psi}(7308440 \mathrm{~Pa})$ \\
Suction pressure of the & $1032 \mathrm{psi}(7115390 \mathrm{~Pa})$ \\
recirculation pump (2) & $77 \mathrm{Mlb} / \mathrm{h}(7768 \mathrm{~kg} / \mathrm{s})$ \\
Mass flow at the core inlet (1) & $25.7 \mathrm{Mlb} / \mathrm{h}(2583 \mathrm{~kg} / \mathrm{s})$ \\
Driven mass flow (3) & $47.1 \mathrm{lb} / \mathrm{ft} 3(754 \mathrm{~kg} / \mathrm{m} 3)$ \\
Density of the water & $6.37 \times 10-5 \mathrm{lb} / \mathrm{ft}-\mathrm{s}(9.48 \times 10-$ \\
Viscosity of the water & $5 \mathrm{~kg} / \mathrm{m}-\mathrm{s})$ \\
Temperature & $278^{\circ} \mathrm{C}\left(532^{\circ} \mathrm{F}\right)$ \\
\hline
\end{tabular}

A modal vacuum analysis was performed to obtain the vibration modes of interest, and the highest natural frequency was used to calculate the wavelength, as well. For this purpose, a spherical domain was created (see Figure 4). It represents the fluid, and its size is equal to or less than half of the wavelength estimated by

$$
\lambda=\frac{c}{f},
$$

where $\lambda$ is the wavelength, $c$ is the speed of sound in the media, and $f$ is the highest natural frequency in a vacuum.

The mesh of the fluid domain and the structure was generated. It had 431646 tetrahedral elements with 605585 nodes. The element type used for the fluid domain was FLUID221, and for the structure was SOLID187. The boundary conditions were the following: (1) the diffusers were fixed at the bottom end, (2) the inlet of the riser was 


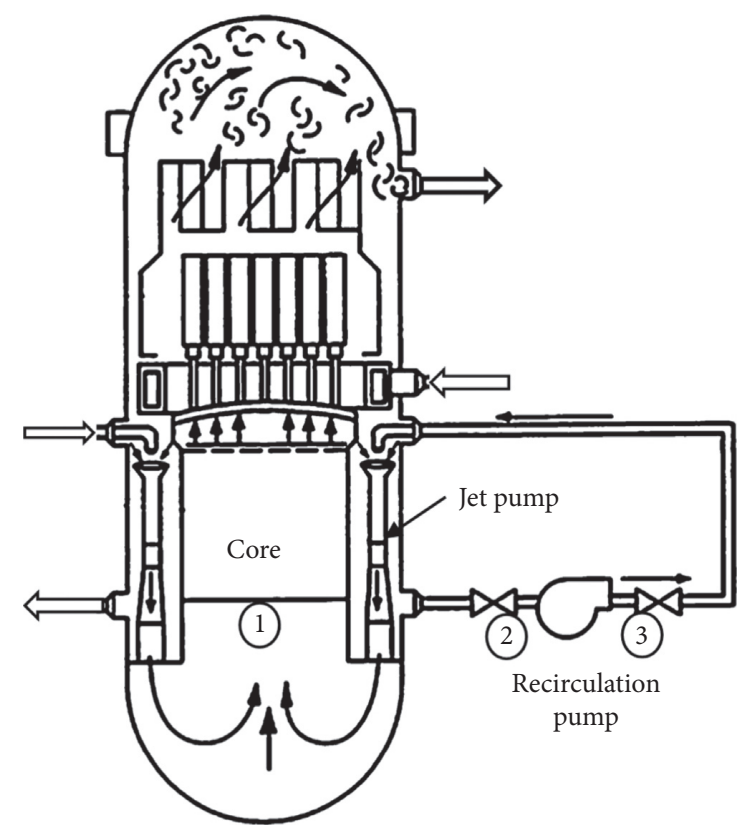

Figure 3: Zones in which the parameters reported in Table 1 take place [11].

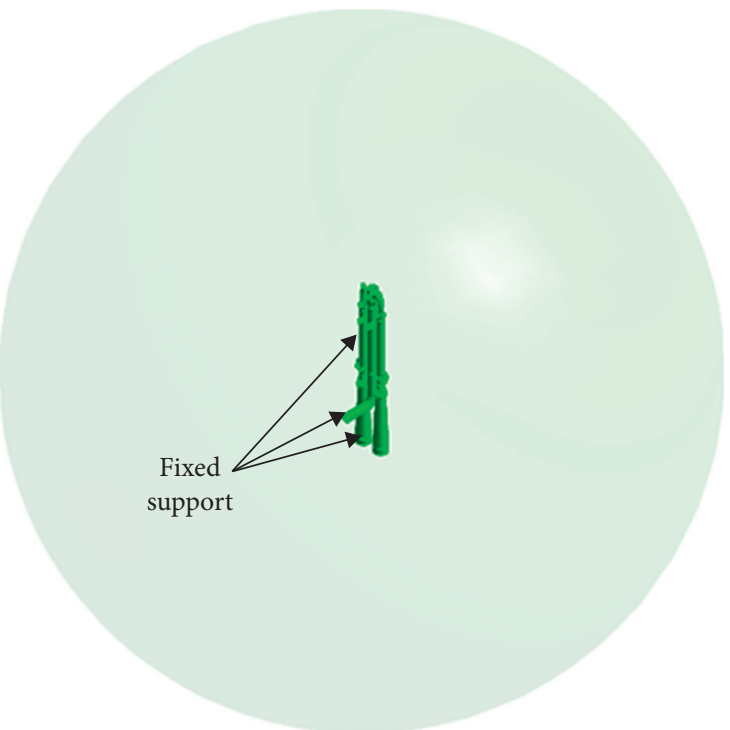

FIgURE 4: Volume control used in the evaluation of the natural frequencies of a jet pump assembly.

fixed, and (3) the top part of the riser was fixed at the riser brace. Figure 5 illustrates the first four modes of vibration, and Table 2 summarizes the results.

The calculation of the natural frequency of the jet pump assemblies considered the fluid that surrounds them. These results were compared with those reported in previous works. Specifically, Stevens et al. [14] used the Finite Element Method. The model was made with beam elements and considers the mass of water inside and outside the assembly of the jet pumps. Castro et al. [15] evaluated the leakageflow-induced vibration of a slip joint in a jet pump. The natural frequencies were evaluated with different gaps at the slip joint. Cuahquentzi et al. [16] determined the natural frequencies and the modes of vibration of the jet pumps with a 3D model. Cuamatzi-Meléndez and Flores-Cuamatzi [17] analyzed the response of the natural frequencies versus the displacement, velocity, and acceleration of the structure. All the results are within an acceptable range. Regarding the case of interest, the first natural frequency, in this paper, is greater than $25 \mathrm{~Hz}$.

\subsection{Evaluation of the Frequency of the Vortex Generation}

5.2.1. Analysis of the Fluid Flow around the Jet Pump Assemblies. The jet pump assembly and the flow through it have been considered in this analysis. The objective was to evaluate the flow and identify the most affected region by the cross flow. A fluid transient analysis was carried on with Fluent ANSYS ${ }^{\circledR}$ code. The symmetry of the cylindrical annular region was considered and only one-fourth was modeled (Figure 6). A hybrid mesh with 5956563 cells was generated. The minimum mesh quality of the orthogonal quality metric was 0.17 , and the average was 0.87 . The boundary conditions and the control volume are shown in Figure 7. It is important to keep in mind that the speed of the fluid was considered, instead of the mass flow. In accordance with our experience, a stable simulation was developed.

The zone where the fluid changes the direction and is collected by the nozzle of the recirculation system is of interest. Its details are shown in Figure 8. In this place, the fluid was modeled with tetrahedral, hexahedral, pyramidal, and wedge elements. The mesh of the zone of the diffuser, which is close to the outlet nozzle, has an average size of $0.02 \mathrm{~m}$. On the other hand, the walls of the jet pumps and the outlet nozzle were modeled with the inflation smooth transition command of ANSYS. A smooth transition of the size of the elements was obtained. Four layers of elements were developed across the thickness. They had a 0.27 transition ratio, and the growth rate was 1.2.

Regarding the turbulence method, the realizable $\mathrm{k}-\varepsilon$ model was used. The wall treatment was simulated with the standard wall functions. The numerical evaluation was done with the pressure-base coupled solver. The absolute criterion was used in the evaluation of the convergence. The range of convergence was 0.001 for the continuity equation, velocity, $k$, and $e$.

The time step was determined in the following way. Initially, the vortex frequency was estimated using the Strouhal number. In the case of a cylinder under cross flow, it was determined with the following relationship, which considers the case of a free stream flow:

$$
f_{s}=\frac{S_{t} U}{D}=\frac{0.26(0.58)}{0.345}=0.44 \mathrm{~Hz}
$$

where $f_{s}$ is the vortex shedding frequency, $S_{t}$ is the Strouhal number, $U$ is the free stream flow velocity, and $D$ is the cylinder diameter. For this work, the average diameter of the conical section was considered $(0.345 \mathrm{~m})$. The Strouhal number varies in accordance with the Reynolds number $\left(S_{t} \approx 0.26\right.$ was assumed). The speed is monitored under 


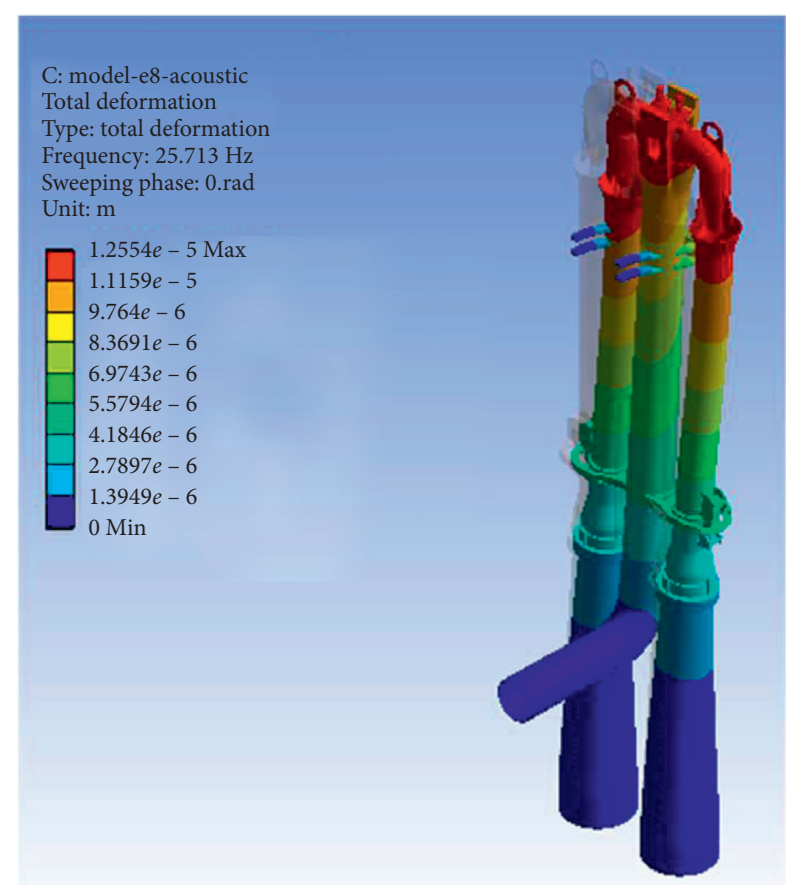

Mode 1

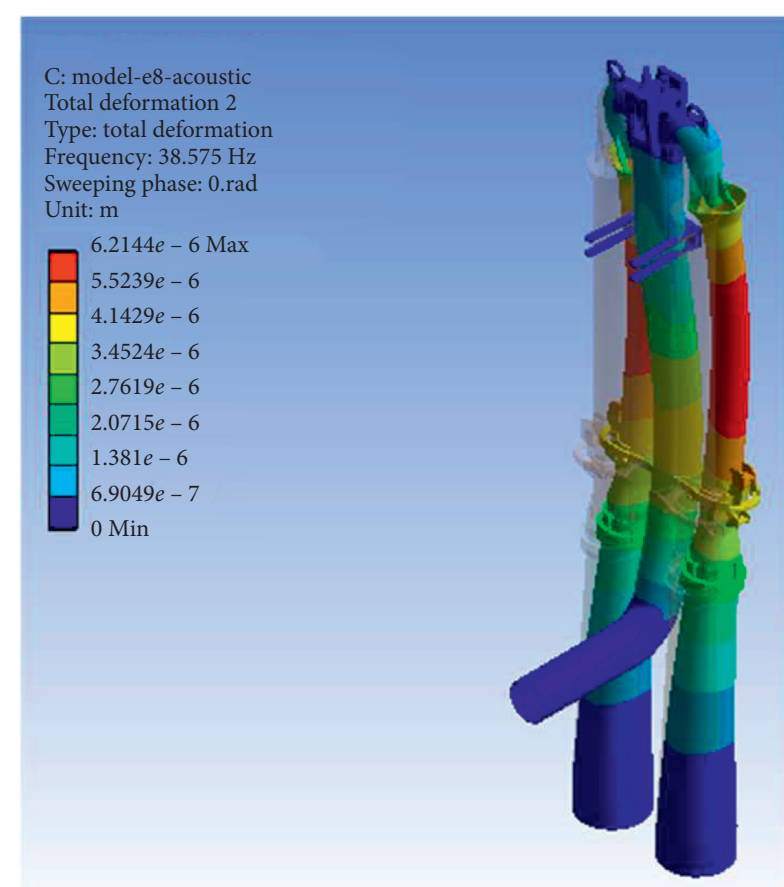

Mode 2 (a)

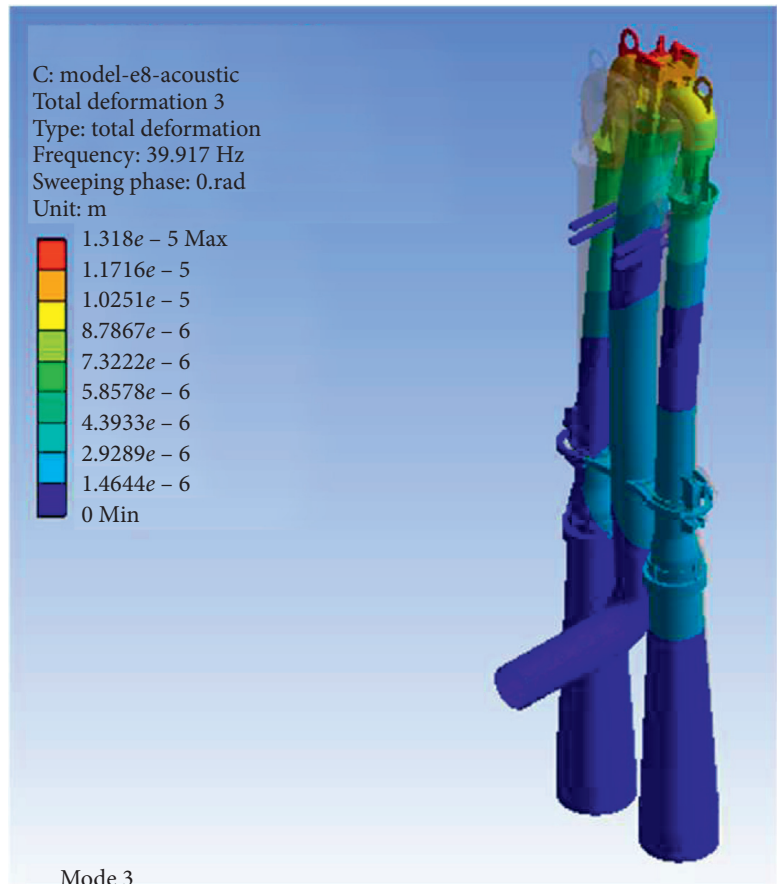

(b)

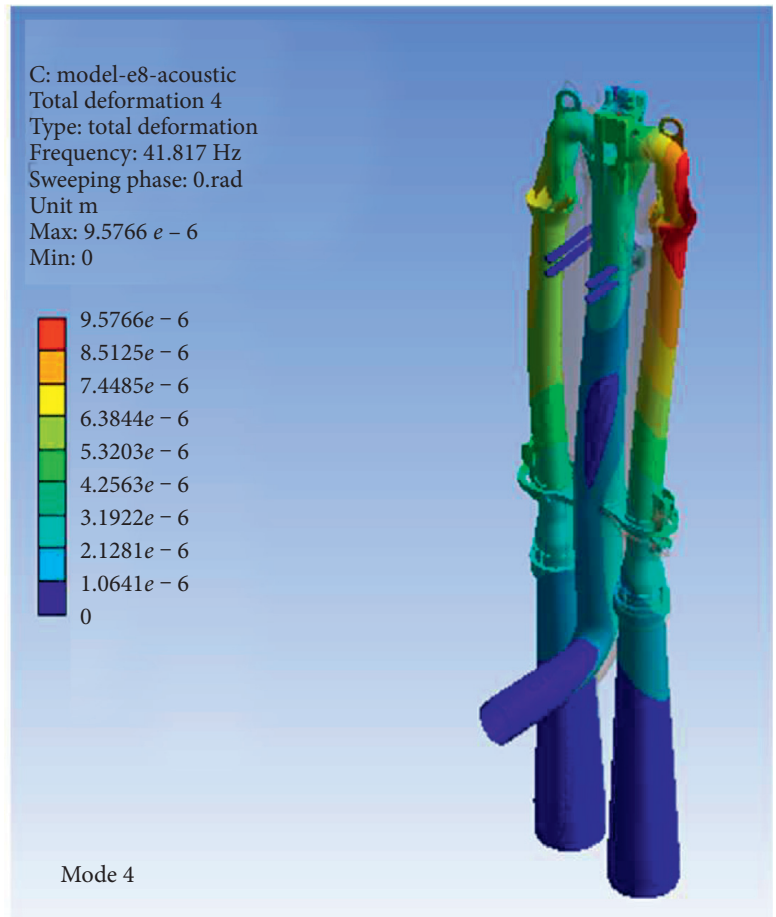

(d)

Figure 5: First four modes of vibration of a jet pump assembly.

Table 2: Natural frequencies of the jet pump assembly.

\begin{tabular}{lccccc}
\hline Vibration mode & $\begin{array}{c}\text { This paper } \\
(\mathrm{Hz})\end{array}$ & $\begin{array}{c}\text { Stevens } \\
\text { et al. [14] }(\mathrm{Hz})\end{array}$ & $\begin{array}{c}\text { Castro } \\
\text { et al. [15] }(\mathrm{Hz})\end{array}$ & $\begin{array}{c}\text { Cuahquentzi } \\
\text { et al. [16] }(\mathrm{Hz})\end{array}$ & $\begin{array}{c}\text { Cuamatzi-Meléndez and } \\
\text { Flores-Cuamatzi [17] }(\mathrm{Hz})\end{array}$ \\
\hline 1 & 25.7 & 27.9 & 25.7 & 25.6 & 24.8 \\
2 & 38.6 & 30.7 & 38.6 & 32.3 & 28.3 \\
3 & 39.9 & 34.6 & 39.9 & 35.7 & 30.1 \\
4 & 41.8 & 35.3 & 41.8 & 39.7 & 33.2 \\
\hline
\end{tabular}




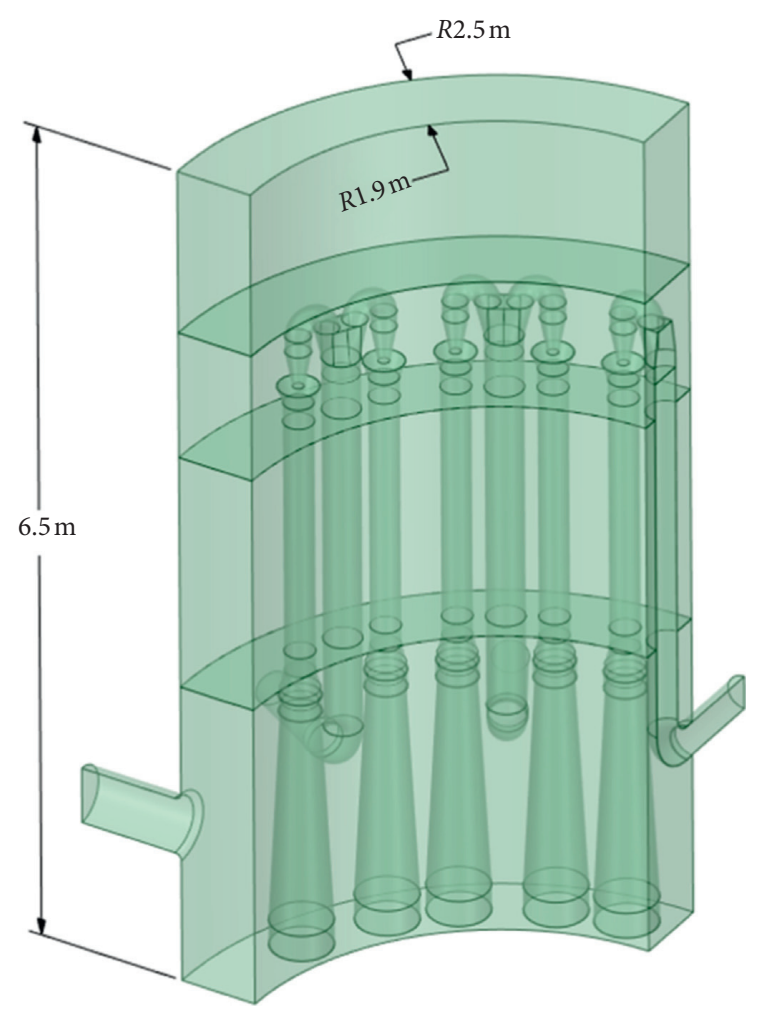

FIgURE 6: Main dimensions of the volume of control.

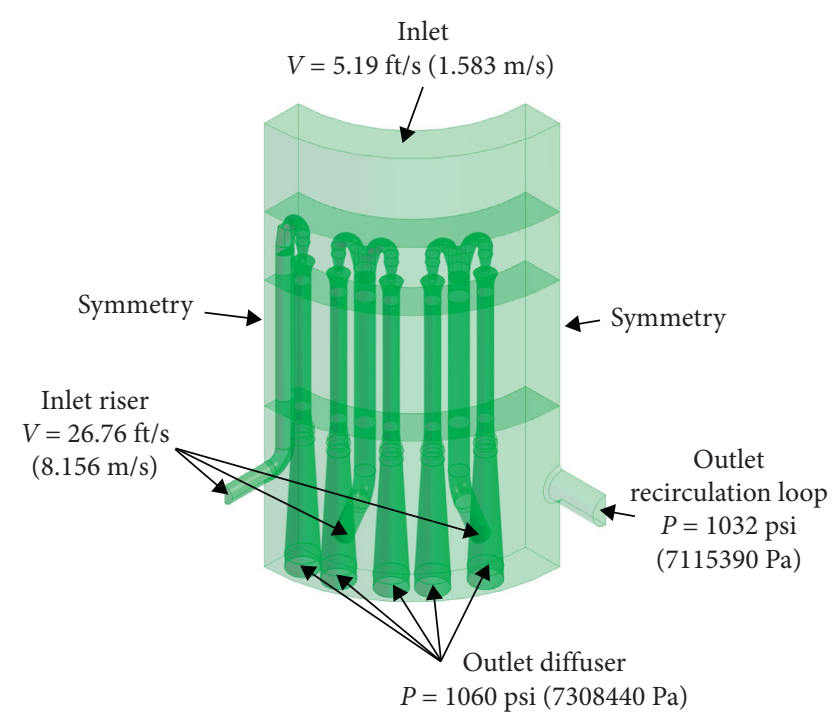

FIgURE 7: Control volume and its boundary conditions.

stable conditions $(U=0.58 \mathrm{~m} / \mathrm{s})$. The period $(T)$ was calculated with the following equation:

$$
T=\frac{1}{f_{s}}=\frac{1}{0.44}=\approx 2.27 \mathrm{~s} .
$$

The time step was obtained when the period was divided by $20(2.27 \mathrm{~s} / 20=0.11 \mathrm{~s} \approx 0.1 \mathrm{~s})$. This is a reference parameter. In this work, it was $0.1 \mathrm{~s}$.

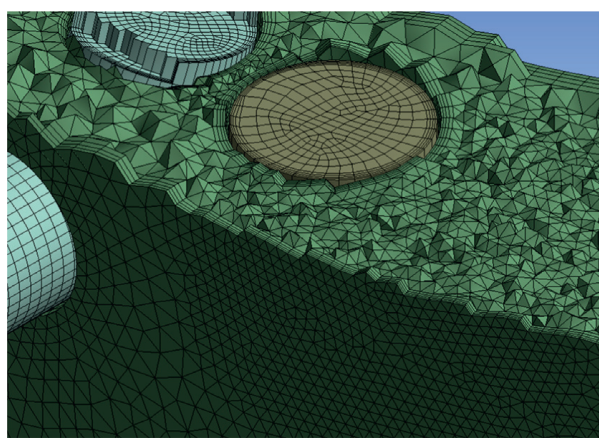

FIGURE 8: Detail of the mesh in the zone of interest.

Figure 9 illustrates the fluid streamlines that envelope the jet pumps in the annular region of the reactor. The left image (a) shows that the fluid moves axially at the top and the middle region of the pumps. Most of the cross flow takes place over the pump diffuser, close to the outlet nozzle of the recirculation loop. It has a diagonal direction in most of this region. The image on the right (b) has spheres that indicate the movement of the fluid, which is from the top to the bottom. It is observed that the spheres of the central zone are being sucked by the recirculation loop. Alternatively, the velocity of the flow, at both sides of the inlet nozzle, is lower.

In this place, the shape of the vortices is complex because their movements have components along the three directions $(x, y, z)$. Figure 10(a) shows that the fluid flows from the left to the right in a diagonal path. It heads to the suction point.

Once that the flow of water has gone around the diffusor, vortices can be developed. For this reason, six points were chosen at three different levels. They are identified in Figure 10(a) and are shown in a plant view in Figure 10(b) with red dots. In this way, irregular vortices can be evaluated simultaneously.

The ASME code establishes that a cross flow is a flow perpendicular to the structural longitudinal axis. In the case of an inclined cylinder with respect to the direction of the flow, the shedding frequency varies as $f_{s}(\theta)=f_{s}(\theta=0) \cos \theta \cdot \theta$ is the angle of inclination of the axial axis of the cylinder with respect to the orientation of such axis, when the flow is perpendicular to the cylinder [18]. Under this scope, the following geometrical considerations were established. The $x-z$ plane is perpendicular to the structural longitudinal axis (Figure $10(\mathrm{~b})$ ). As a result, the velocity $V_{z}(t)$ is evaluated along the $z$-direction at the six monitoring points (Figure 11). It is observed as a cyclic flow velocity.

An initial estimation of the frequency of the vortex generation was done with the data recorded with the monitoring points. The signal of the fifth point in the range between 20 and 30 seconds was considered. It can be observed that around 4.4 cycles take place. The approximate frequency was $0.44 \mathrm{~Hz}(4.4 / 10 \mathrm{~s})$. It is close to the value estimated with equation (13).

This data was evaluated with the PSD to obtain the resonance condition in the dominium of frequencies (Figure 12). The signals were grouped with the same amplitude 


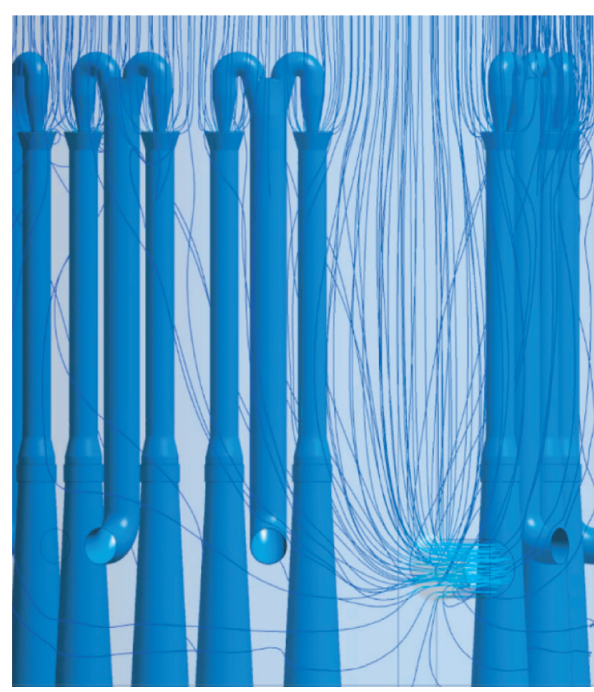

(a)

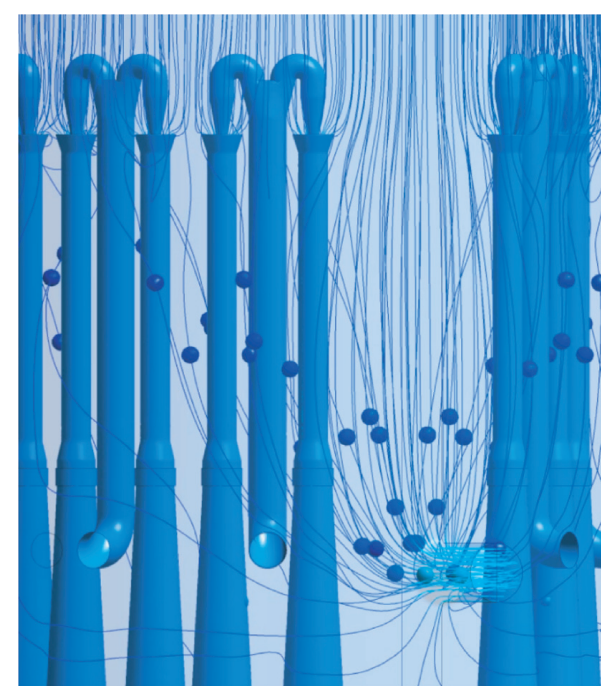

(b)

FIGURE 9: Fluid streamlines around the jet pumps in the cylindrical annular region of a BWR.

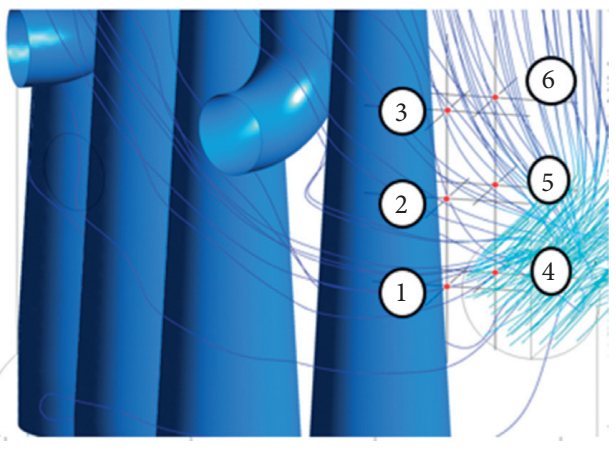

(a)

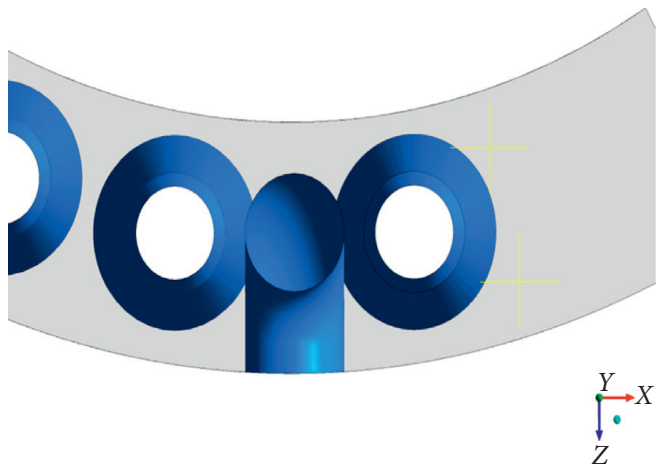

(b)

Figure 10: Points of monitoring. (a) Isometric view and (b) Plant view.

and frequency with which they repeat. The energy peaks were around $0.02 \mathrm{~Hz}, 0.08 \mathrm{~Hz}, 0.18 \mathrm{~Hz}, 0.25 \mathrm{~Hz}$, and $0.42 \mathrm{~Hz}$. The maximum peak of energy was obtained at point 6 . The frequency of vortex shedding is $0.42 \mathrm{~Hz}$.

\subsubsection{Detailed Analysis of the Cross Flow in the Region of} Interest. The flow of fluid around the jet pumps is of great interest. Great attention was paid to the diffuser which is closest to the suction point. It is affected by cross flow. A fine mesh was required to get precise details about the vortex generation. For this purpose, the elements of the fluid mesh were reduced, as is shown in Figure 13. The boundary conditions are illustrated in Figure 14. The flow velocity at the input of the volume control is the driving flow velocity.

An advanced mesh generator, known as ICEM CFD, was used to generate a hexahedral mesh. It is appropriate for a fluid analysis. However, its application to complex geometries is difficult. In general terms, the control volume is divided into blocks. Each one of the axes of the blocks is associated with the curves of the geometry. Then, each axis is divided according to the desired mesh size. In the final step, it is evaluated if the mesh has the required quality. For the problem at hand, the size of the mesh on the surface of the jet pumps was $0.0003 \mathrm{~m}$ and the minimum value of the orthogonal quality was 0.17 . Under these conditions, the mesh has 4877002 cells (see Figure 13).

This mesh was loaded in the fluent code. The inexistence of elements with negative volume was verified, and the quality of the mesh was evaluated again. Then, the density and the viscosity of the fluid were introduced. The six monitoring points, the time step, the model of turbulence, and the convergence criterion, mentioned above, were considered. 


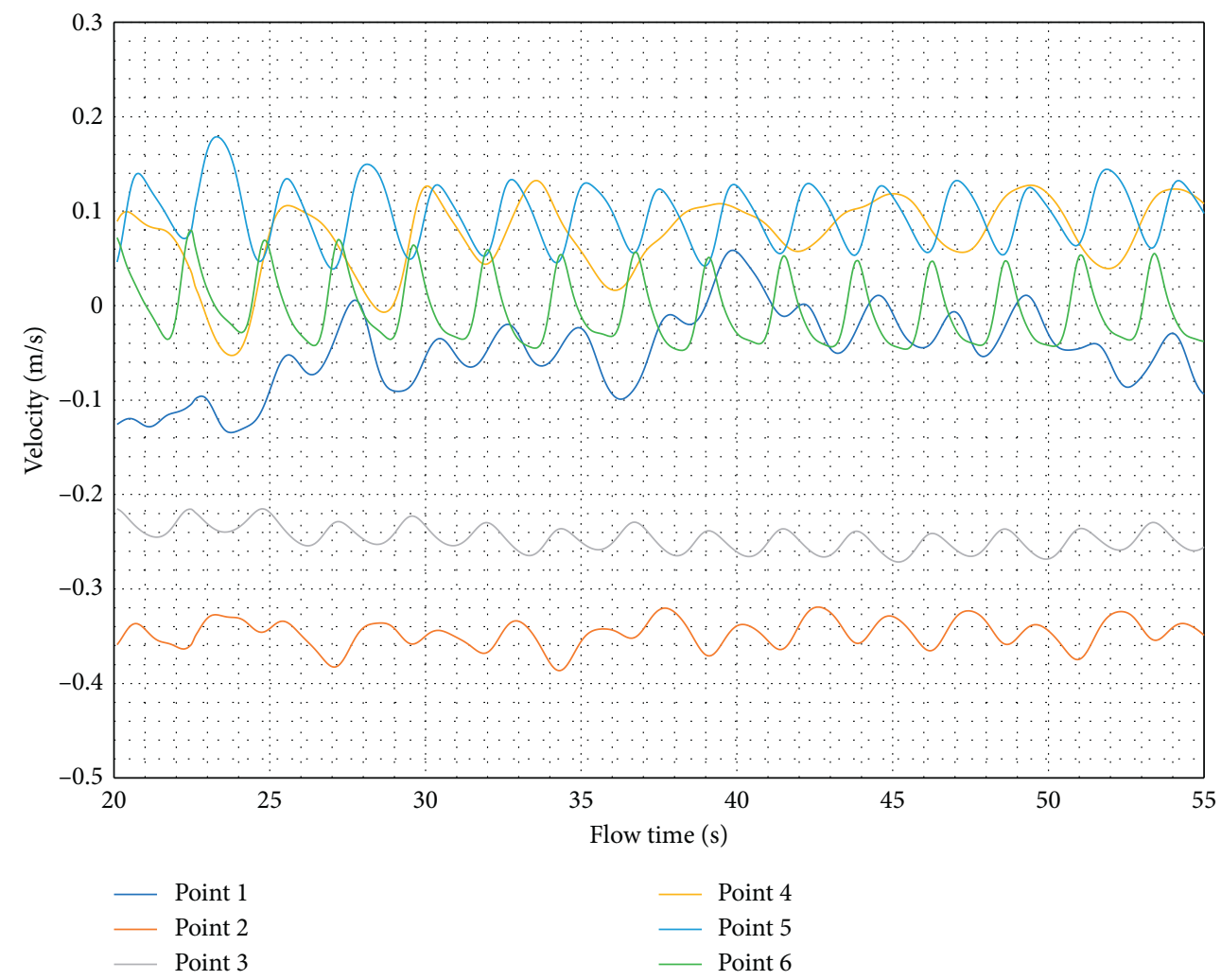

FIGURE 11: Velocity in the function of time along the $z$-direction $V_{z}(t)$.

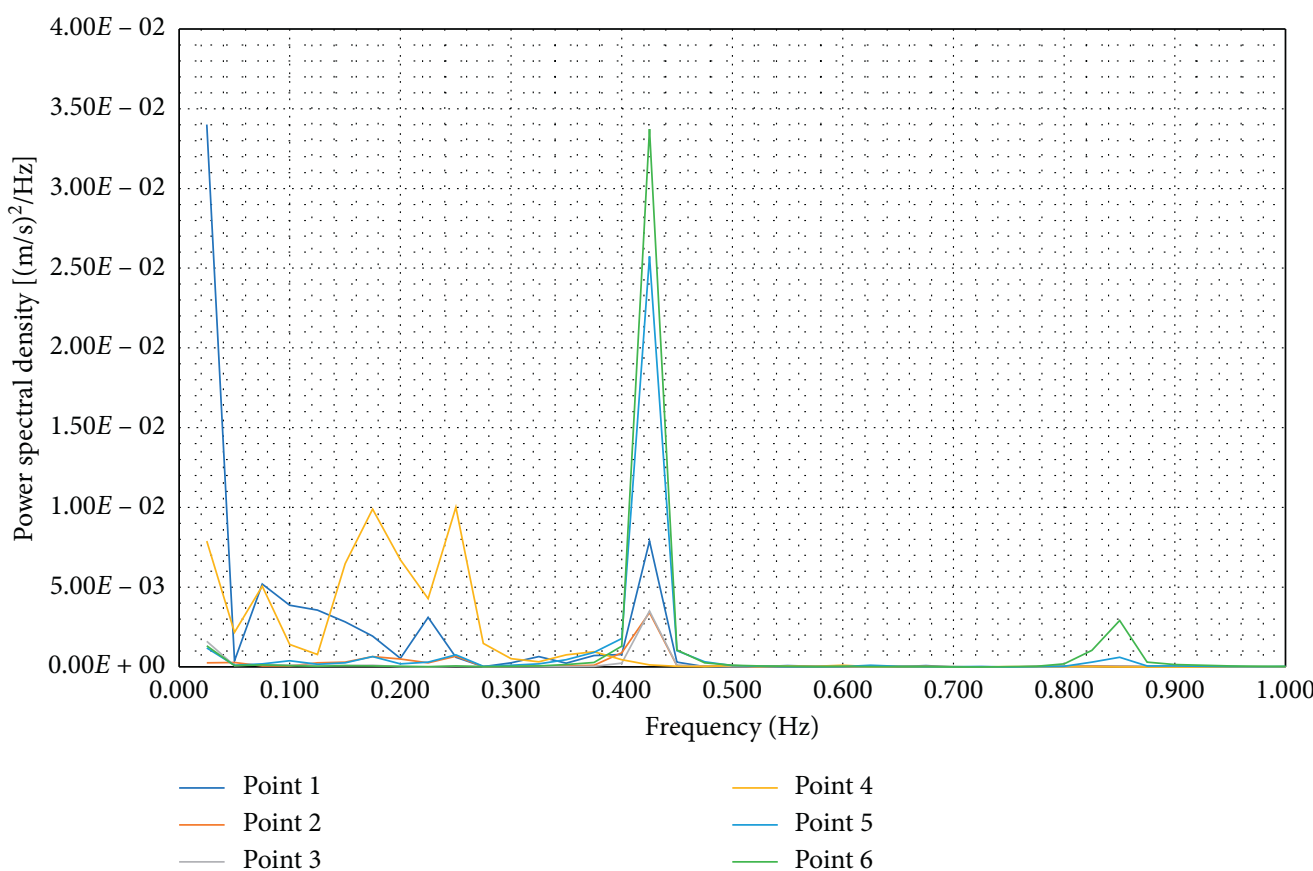

Figure 12: Power Spectral Density versus frequency.

The velocity $V z(t)$ versus time (Figure 15 ) was also graphed. A cyclic behavior is not markedly observed in all cases. The data of point 1 has the greatest amplitude. In an initial analysis, the number of cycles in the range between 20 and 30 seconds was considered. In this case, a frequency around $4.8 \mathrm{~Hz}$ was observed. Therefore, the frequency of vortex generation of $0.48 \mathrm{~Hz}$ was also observed. This is in line with the analysis of Figure $12(0.42 \mathrm{~Hz})$. 


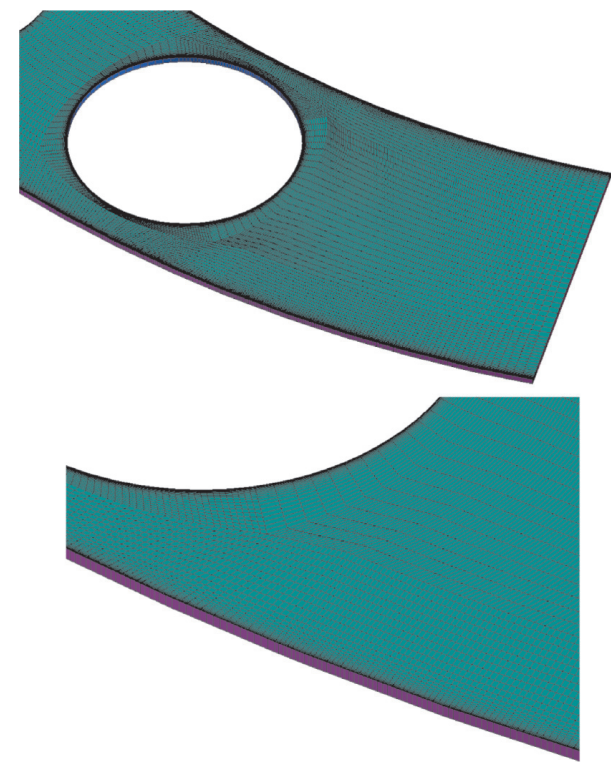

(a)

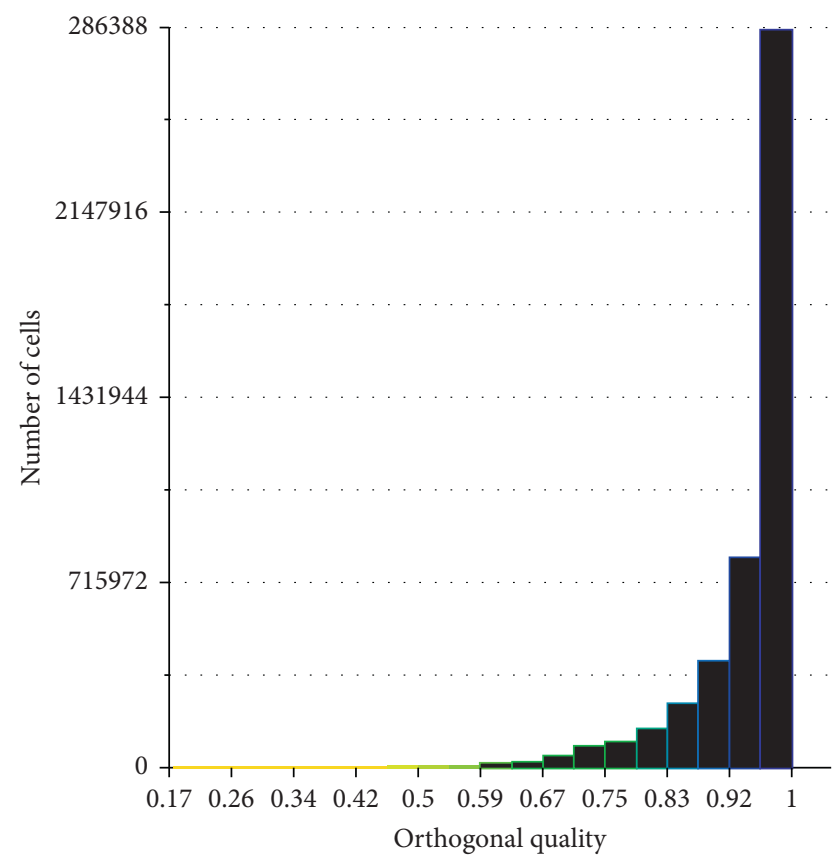

(b)

Figure 13: Mesh and quality. (a) Mesh internal detail and (b) orthogonal quality.

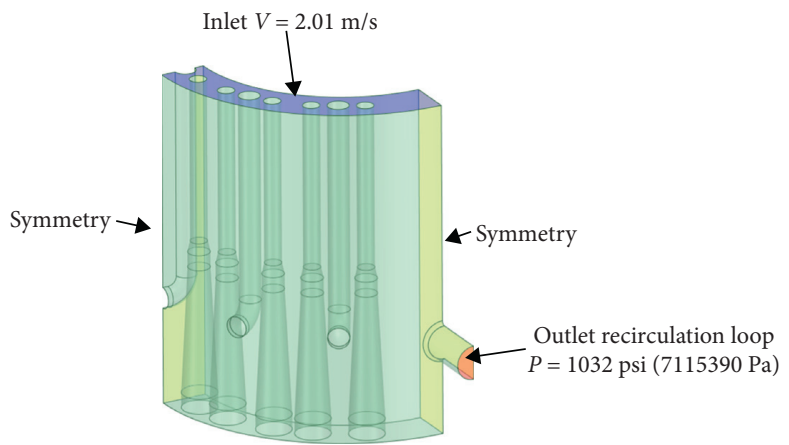

FIGURE 14: Control volume and boundary conditions considered in the analysis of the zone of interest.

The PSD of this data is illustrated in Figure 16. Energy peaks can be observed at $0.03 \mathrm{~Hz}, 0.1 \mathrm{~Hz}, 0.15 \mathrm{~Hz}, 0.47 \mathrm{~Hz}$, and $0.95 \mathrm{~Hz}$. The maximum values were obtained at 1 and 2 . Their frequencies were $0.03 \mathrm{~Hz}$ and $0.48 \mathrm{~Hz}$. Alternatively, the lowest peak pf energy was registered with $0.95 \mathrm{~Hz}$ frequency.

If Figures 12 and 16 are compared, it can be observed that the peaks of energy are higher in the range between 0.02 and $0.04 \mathrm{~Hz}, 0.42 \mathrm{~Hz}$, and $0.48 \mathrm{~Hz}$. The critical frequency is $0.48 \mathrm{~Hz}$, which was obtained from Figure 15, when the number of cycles is counted in such figure. It is in accordance with the peak of energy observed in Figure 16.

The $Q$ criterion was used to visualize the vorticity in the region of interest. In this case, their shape was irregular (Figure 17). They were directed toward the suction nozzle.

\section{Analysis of the Results}

Two symmetric vortices are generated at the neighborhood of a cylindrical body, when the flow is perpendicular to its axial axis. Under these conditions, the reduced speed range $V_{r}$ is within the interval, $1.5<V_{r}<2.5$. They are unstable and downstream they collapse. In the range of $2.7<V_{r}<3.8$, the vortices are generated alternately, and the resonant frequency of the structure occurs at a rate of twice the vortex generation frequency $\left(2 f_{s}\right)$. In the two regimes mentioned above, the vibration is parallel to the direction of flow. On the other hand, in the range between $4<V_{r}<8$, transverse vibration occurs [17]. Any oscillation is suppressed if $C_{n}>64$. This is considered by the ASME code. 


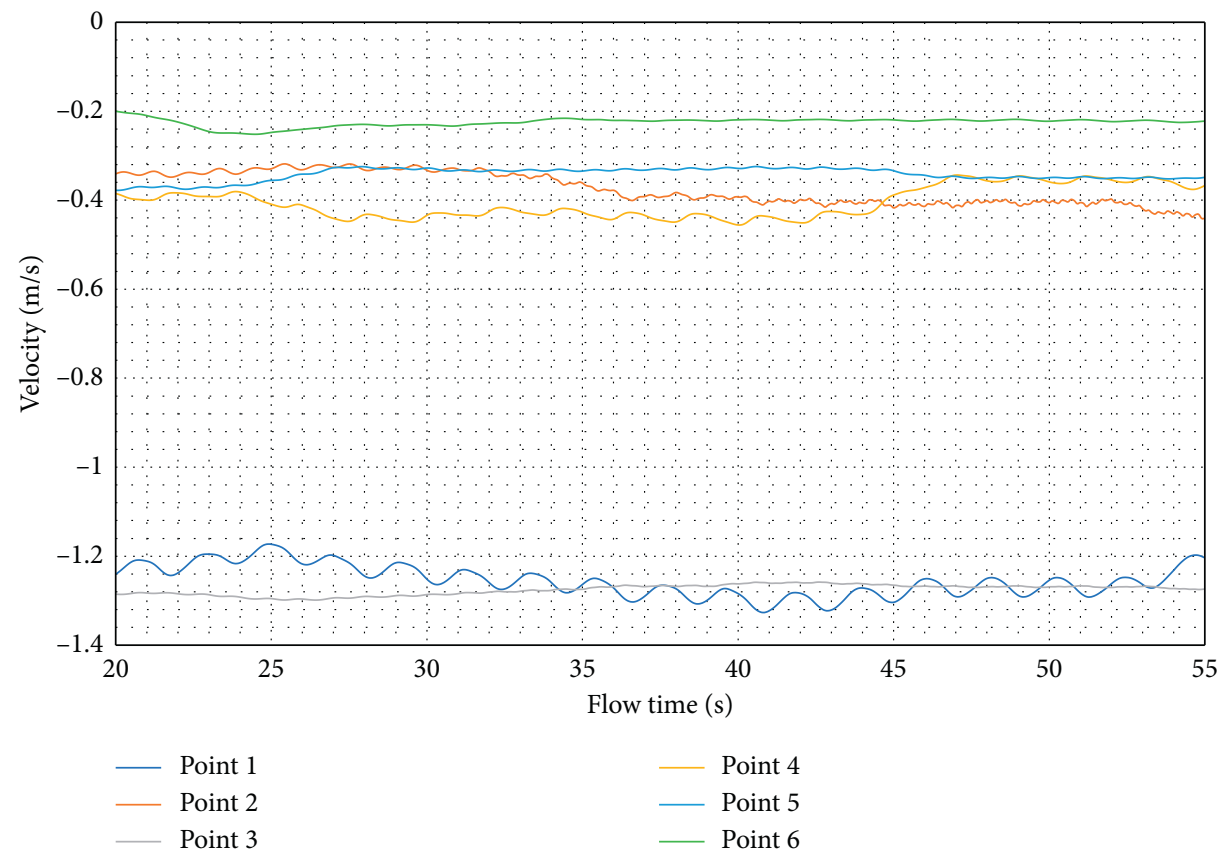

FIGURE 15: Velocity in the function of time along the $z$-direction $V_{z}(t)$.

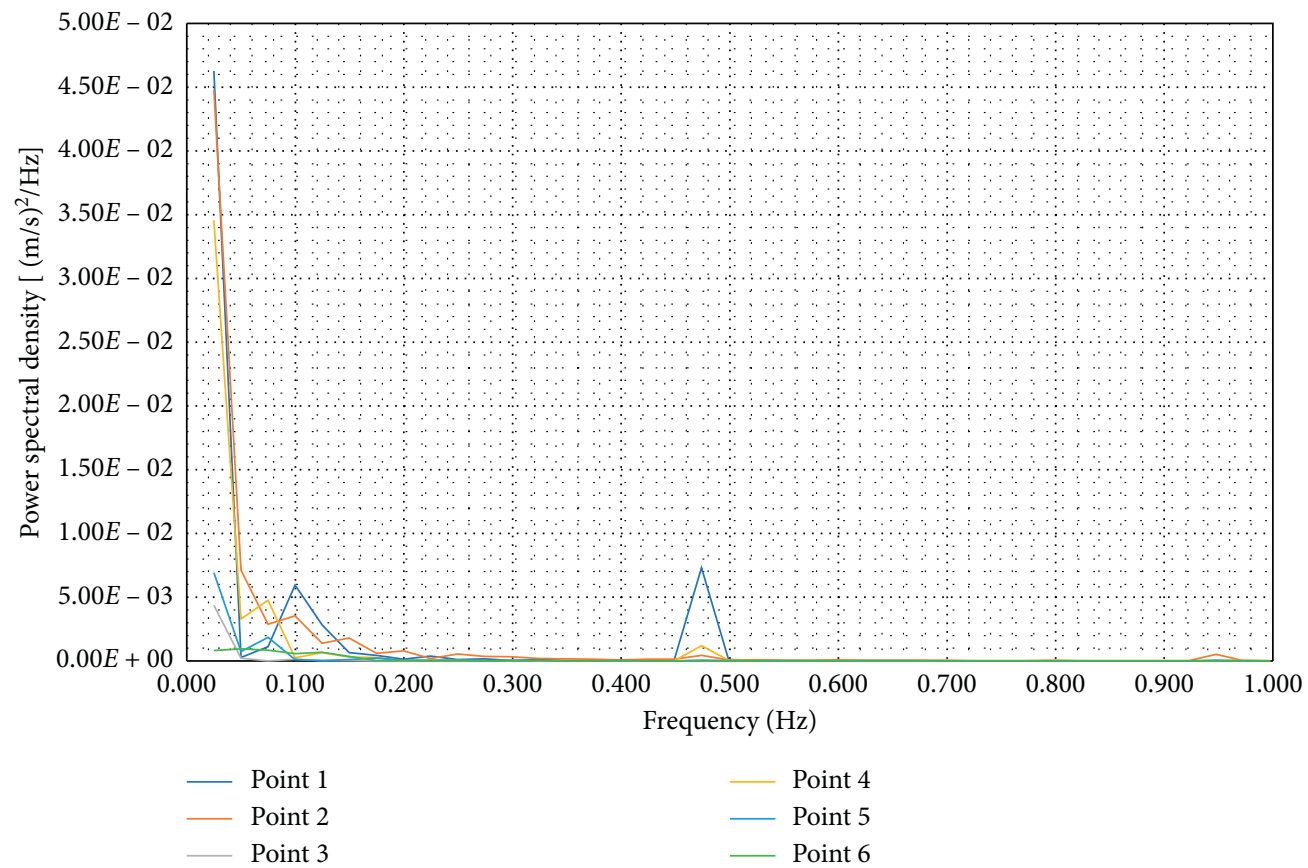

Figure 16: Power Spectral Density versus frequency.

$\mathrm{N}, \mathrm{N}-1324.1$ of Section III of the ASME Code is a nonmandatory appendix. The following criteria have been established for cylindrical bodies [3,18].

(1) $V_{r}<1$, oscillation is avoided

(2) $C_{n}>64$, any oscillation is suppressed

(3) $V_{r}<3.3 y C_{n}>1.2$, lift oscillation is avoided, and drag oscillation is inhibited
(4) $f_{s} / f_{n}<0.7$ or $f_{s} / f_{n}>1.3$, the lift oscillation is only avoided

$V_{r}$ is the reduced velocity, $C_{n}$ is the reduced damping, $f_{s}$ is the frequency of vortex generation, and $f_{n}$ is the natural frequency of the structure.

The criteria of the ASME code were taken as a point of reference to compare them with the results obtained numerically. It is emphasized that the cited appendix is for 


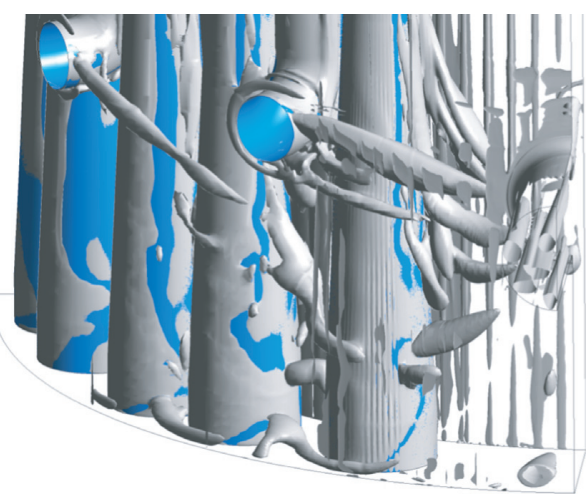

FIGURE 17: Vortices at the region of interest.

cylindrical geometry. However, there is a conical section in the region of the problem at hand where the cross flow effects are the greatest. For this reason, an average value of the diameter was considered.

In relation to the case of interest, the first natural frequency is $25.7 \mathrm{~Hz}$. If the fourth criterion, mentioned above, is followed, it is fulfilled. The lift oscillation is prevented.

$$
\frac{f_{s}}{f_{n}}=\frac{0.48}{25.7}=0.019<0.7
$$

The first criterion considers the reduced velocity. If this parameter is lower than 1, any type of oscillation is avoided.

$$
V_{r}=\frac{U}{f_{n} D}=\frac{0.58 \mathrm{~m} / \mathrm{s}}{25.7 \mathrm{~Hz}(0.345 \mathrm{~m})}=0.065<1 .
$$

The frequency of vortex generation is within the allowable range. It was verified that the cross flow does not introduce any vibration.

\section{Conclusions}

Cross flow is one of the degradation mechanisms, which has to be evaluated for BWR-5 jet pump assemblies. It induces vibration that may affect the integrity of the pumps and the reactor pressure vessel. Jet pumps operate submerged in water, so their mass must be considered to obtain their natural frequencies. Due to the complexity of an experimental analysis, a simulation by a numerical analysis can be done. For the problem under study, the Fluid-Structure Interaction (FSI) is an advisable approach.

Regarding vortex analysis, a transient fluid analysis was required, so an evaluation by Computational Fluid Dynamics was appropriate for this purpose. The result showed that most of the fluid around the jet pumps flows axially and the area, which is closest to the suction of the recirculation loop, is the most affected by the cross flow. Critical points were selected at this region, and by means of the PSD, in combination with manual peak counting in $z$-direction velocity graphs, the vortex frequency was obtained.

The results show that, under normal operating conditions, cross flow is not a mechanism that affects the performance of jet pumps. The natural frequencies of the jet pump assemblies are greater than $25.7 \mathrm{~Hz}$, while the frequency due to the vibration generated by the flow is approximately $0.48 \mathrm{~Hz}$. Resonance conditions are unlikely.

The $Q$ criterion was used to evaluate the turbulence at the region, which is close to the suction point. The vortices, which were generated, have an irregular shape and they were directed toward the suction direction.

If the nonmandatory appendix N-1300 of Section III of the ASME code is taken as reference, it can be verified that the acceptance criteria are fulfilled. It should be noted that this section is limited, because it focused on tubes and bundles of tubes. As it can be seen, the numerical analysis proposed in this paper is adequate for the postulated case.

\section{Data Availability}

The results can be found in the offices of the Mexican Nuclear Regulatory Body, "Comisión Nacional de Seguridad Nuclear $y$ Salvaguardias."

\section{Disclosure}

The conclusions and opinions stated in this paper do not represent the position of the National Commission on Nuclear Safety and Safeguards, where the coauthor P. Ruiz-López is working as an employee. Although special care has been taken to maintain the accuracy of the information and results, all authors do not assume any responsibility for the consequences of its use. The use of particular mentions of countries, territories, companies, associations, products, or methodologies does not imply any judgment or promotion by all the authors.

\section{Conflicts of Interest}

The authors declare that there are no conflicts of interest regarding the publication of this paper.

\section{Acknowledgments}

The authors kindly acknowledge the grant for the development of Project 211704. It was awarded by the National Council of Science and Technology (CONACYT).

\section{References}

[1] EPRI-NRC Technical Exchange Meeting, BWR Vessel and Internals Project Update, p. 17, Electric Power Research Institute, Washington, DC, USA, 2019.

[2] EPRI, BWRVIP-41 BWR Jet Pump Assembly Inspection and Flaw Evaluation Guidelines, Electric Power Research Institute, Washington, DC, USA, 2014.

[3] S. Kaneko, Flow-Induced Vibrations: Classifications and Lessons from Practical Experiences, pp. 359-361, Elsevier, Amsterdam, Netherlands, Second edition, 2013.

[4] P. Ruiz, "Integridad estructural de las Bombas de Chorro de un reactor BWR, ante la presencia de defectos relevantes," Ciudad de México: Tesis de Maestría, Instituto Politécnico Nacional, Mexico City, Mexico, 2014.

[5] GE Nuclear Energy, BWR/6 General Description Of A Boiling Water Reactor, GE Nuclear Energy, Wilmington, NC, USA. 
[6] C. Q. Howard and B. S. Cazzolato, Acoustic Analyses Using $M A T L A B^{\circledR}$ and $A N S Y S^{\circledR}$, pp. 7-10, CRC Press, New York, NY, USA, 2015.

[7] "8.4. Acoustic fluid-Structural Interaction (FSI)," 2020, https:// ansyshelp.ansys.com/account/secured?returnurl=/Views/Secured/ corp/v201/en/ans_thry/thyacous_afsi.html.

[8] “4.1.1. Reynolds (Ensemble) Averaging," 2020, https://ansyshelp. ansys.com/account/secured?returnurl=/Views/Secured/corp/v202/ en/flu_th/flu_th_sec_reynolds_averaging.html.

[9] “4.3.3. Realizable $k$ - $\varepsilon$ Model," 2020, https://ansyshelp.ansys. com/account/secured?returnurl=/Views/Secured/corp/v202/ en/flu_th/flu_th_sec_turb_realizke.html.

[10] ASME, Flow-Induced Vibration With Aplications To Component Failure Analysis, American Society of Mechanical Engineers, New York; NY, USA, 2017.

[11] USNRC Technical Training Center, BWR/4 Technology Manual (R-104B), USNRC Technical Training Center, Rockville, MA, USA.

[12] Y. A. Çengel and A. J. Ghajar, Heat And Mass Transfer: Fundamentals \& Applications, McGraw-Hill, New York, NY, USA, 5th edition, 2015.

[13] IAEA-TECDOC-1471, Assessment And Management of Ageing of Major Nuclear Power Plant Components Important to Safety: BWR Pressure Vessel Internals, p. 29, International Atomic Energy Agency, Vienna, Austria, 2005.

[14] G. L. Stevens, R. A. Mattson, and D. M. Swann, "Jet pump flaw evaluation procedures," in Proceedings of the 8th International Conference On Nuclear Engineering, Baltimore, MD, USA, June 2000, https://www.researchgate.net/publication/ 2638162.

[15] J. C. Castro, E. H. Palafox, I. A. A. Sánchez, L. H. HernándezGómez, P. Ruiz-López, and A. A. Molina, "Analysis of the leakage-flow-induced vibration of a slip joint in a jet pump of a boiling water reactor," Defect and Diffusion Forum, vol. 390, pp. 23-31, 2019.

[16] N. M. Cuahquentzi, L. H. H. Gómez, P. R. López et al., "Evaluation of the structural integrity of the jet pumps of a boiling water reactor under hydrodynamic loading," Defect and Diffusion Forum, vol. 348, pp. 261-270, 2014.

[17] R. Cuamatzi-Meléndez and E. Flores-Cuamatzi, "Modelling fluid-structure interaction of water recirculating flow to predict damage and/or failure in a jet-pump assembly of a nuclear boiling water reactor," Engineering Structures, vol. 206, p. 110155, 2020.

[18] The American Society of Mechanical Engineers (ASME), Boiler and Pressure Vessel Code, Section III, Division I, Appendix N, Subparagraph N-1324.1, pp. 301-302, ASME, New York, NY, USA, 2007. 